\title{
Awareness on Dry Socket and its Management Among Undergraduate Dental Students - A Questionnaire Survey
}

\author{
Baala Vignesh $\mathrm{A}^{1}$ and Madhulaxmi $\mathrm{M}^{2}$ \\ ${ }^{1}$ Saveetha dental college and hospitals Saveetha Institute of Medical \\ and Technical Sciences Saveetha University, Chennai-600077, India \\ ${ }^{2}$ Professor. Department of oral surgery Saveetha dental college and hospitals Saveetha \\ Institute of Medical and Technical Sciences Saveetha University, Chennai-600077, India
}

\section{ABSTRACT}

Dry socket lesion is a post-extraction socket exhibiting exposed bone which is not covered by a blood clot or healing epithelium. This is one of the most common post extraction complication encountered in routine dental practise. This survey was done to check the knowledge and practise in management of dry sockets among undergraduate dental students. An online questionnaire was shared among 95 participants consisting of final year dental students and dental interns. There were 10 sets of close ended questions shared on survey planet. Based on the answers from the survey, the data was compiled and analyzed. Chi square test of statistical analysis was used with the aid of SPSS software version 20.0. The survey was taken up by 31.58\% $(\mathrm{n}=30)$ fourth year students and $68.42 \%(\mathrm{n}=65)$ intern students. More than 60 $\%$ students gave correct responses to questions related to etiology, clinical presentation and management of dry socket. There were a smaller number of students who gave correct answers to the pathogenesis of the condition (51\%). Both final year and intern students displayed an overall good knowledge about dry socket and its management. However, intern students showed better understanding than fourth year students which was statistically significant with $\mathrm{p}<0.05$ to three out of ten questions. It can be concluded that dental students eventually gain better insight in the subject with increasing clinical years.

KEY WORDS: ALVEOLAR OSTEITIS, BACTERIA, EXTRACTION, IRRIGATION, MEDICAMENT, PLASMIN.

\section{INTRODUCTION}

Dry socket, also referred to as fibrinolytic osteitis or alveolar osteitis, is a complication of the post extraction socket (Mamoun, 2018). A dry socket lesion is a postextraction socket exhibiting exposed bone which is

\section{ARTICLE INFORMATION}

*Corresponding Author: madhulaxmi@saveetha.com Received 2nd Aug 2020 Accepted after revision 28th Sep 2020 Print ISSN: 0974-6455 Online ISSN: 2321-4007 CODEN: BBRCBA

Thomson Reuters ISI Web of Science Clarivate Analytics USA and Crossref Indexed Journal

\section{Clarivate
Analytics}

NAAS Journal Score 2020 (4.31) SJIF: 2020 (7.728)

A Society of Science and Nature Publication,

Bhopal India 2020. All rights reserved.

Online Contents Available at: http//www.bbrc.in/

Doi: http://dx.doi.org/10.21786/bbrc/13.8/130 not covered by a blood clot or healing epithelium and exists inside or around the perimeter of the socket for days after the extraction procedure (Bowe et al., 2011). Patients following extraction will not be able to stop the tongue stimulating the socket when food particles get impacted. This mechanical stimulation on the exposed bony structure under the extracted socket which can be acutely painful to touch.(Bowe et al., 2011). The impacted food particles and bacteria present can dislodge the blood clot with the exposed bone and prolong the healing time of the exposed socket.(Sharma et al., 2017).

This phenomenon results in formation of toxins causing irritation of the exposed bone structure, halitosis and jaw pain (Birn, 1970). Though the cause of dry sockets are not well known, there are certain etiological factors

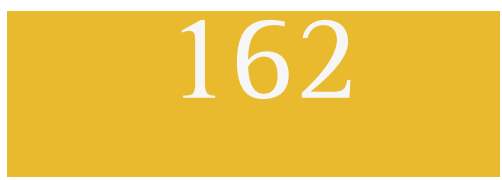


and personal factors like poor oral hygiene, smoking, oral contraceptive use, traumatic extractions with heavy luxation of tooth can correlate with an increased incidence of dry sockets (Catellani et al., 1980). The socket can be completely exposed to the level of the bone or can be lined by infectious food debris or weakly clumped bacterial material.

There can be some amount of healing that is exhibited on the occlusal layers of the socket (Abhinav et al., 2019; Freudenthal et al., 2015; Mamoun, 2018). The basic treatment of dry sockets involves the irrigation of the infected socket using saline or chlorhexidine gluconate, povidine iodine.(Freudenthal et al., 2015) This irrigated socket is filled with a medicaments like zinc oxide eugenol pack(Birn, 1973; Kumar et al., 2015). Measures are taken for optimal visualisation to reduce the contact of irrigation needles with the bone and proper removal of the debris in all aspects of the socket(Nusair and $\mathrm{Abu}$ Younis, 2007). Forceful curettage is contradicted in the case of dry sockets as it can spread the infection. Dry sockets can also be anesthetised and curetted to induce fresh bleeding to facilitate the healing of the socket( $\mathrm{H}, 2011)$. With a rich case bank established over 3 decades we have been able to publish extensively in our domain.

(Abdul Wahab et al., 2017; Abhinav et al., 2019; Eapen et al., 2017; J et al., 2018; Jain and Nazar, 2018; Marimuthu et al., 2018; Patil et al., 2017; Ramadorai et al., 2019; Senthil Kumar et al., 2019; Sweta et al., 2019; Wahab et al., 2018). Based on this inspiration we aim to create an awareness on dry sockets. The aim was to assess and evaluate the knowledge on dry sockets among final year students and intern dental students.

\section{MATERIAL AND METHODS}

An online questionnaire was shared among 95 participants consisting of final year dental students and dental interns. There were 10 sets of close ended questions shared on survey planet. The study was conducted in December 2019. Inclusion criteria were that the participants had to be in their final year or internship year. Prefinal year and specialists were excluded from the study. Participants only willing to answer all the survey questions were included after taking their informed consent. The questionnaire was prepared in a such a way to incorporate all clinical aspects of dry socket. Questions regarding etiology, pathogenesis, clinical features and management of dry socket were precisely framed. The responses of the survey were tabulated with the use of excel sheets. The analysis of the responses was done with the help of a statistical software SPSS version 20.0. Chi square tests were used to check for statistical significance.

\section{RESULTS AND DISCUSSION}

The study showed that out of the 95 participants who took part in the survey, $31.58 \%$ of them were fourth year students and $68.42 \%$ of them were intern students (figure 1). 17.89\% fourth year and 46.32\% intern students answered correctly for the question on the most common site of incidence for alveolar osteitis as mandibular posterior region. This response did not have any statistically significant difference among the students in different years of study $(\mathrm{p}=0.097>0.05$.(figure 2). $12.63 \%$ fourth year and $41.05 \%$ interns answered correctly to the question, what is the pathogenesis for dry sockets as plasminogen pathway. The response has a statistical significance and the interns were better aware of the pathogenesis of dry sockets when compared to final years with $\mathrm{p}=0.036<0.05$ (figure 3 ).

Figure 1- represented the frequency of fourth year students and interns who took part in the survey. $\mathrm{X}$ axis represents the year of study of the participants and $Y$ axis represents the number of fourth year and intern students who participated in the survey.

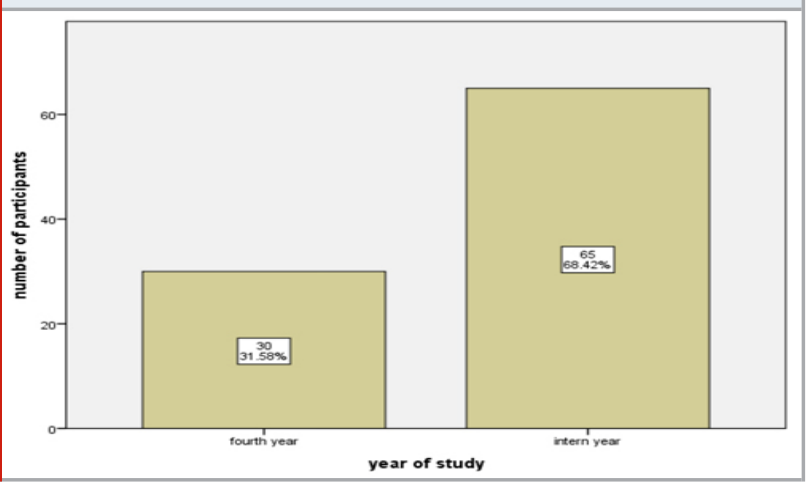

Figure 2: Represents association between the response to the question, dry socket is common in which quadrant. $\mathrm{X}$ axis represents year of study and $\mathrm{Y}$ axis represents the number of participants. $64.21 \%$ participants agreed that mandibular posterior quadrant was the most common site (purple). The association of response to the year of study was not statistically significant with $p$ value $=0.097>$ 0.05 using chi square test.

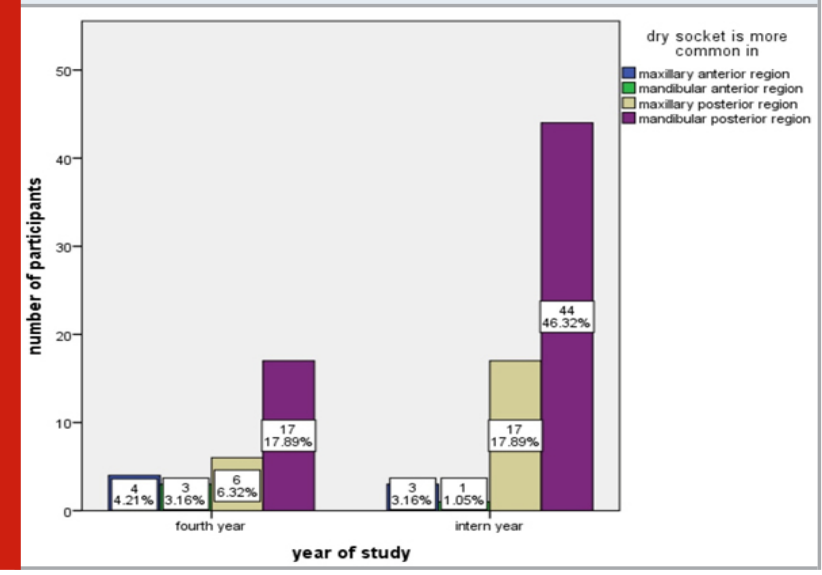

16.84\% fourth year and 46.32\% interns answered correctly to the question, dry sockets occurrence is seen after how many days of tooth extraction as 2-5 days. The responses did not have any statistical significant 
differences among the students in different years of study $(p=0.14>0.05$ ) (figure 4). $21.05 \%$ fourth year and $65.26 \%$ interns answered correctly to the question, is smoking a etiological cause for the incidence of dry socket as yes. The responses were statistically significant as the most interns responded correctly when compared to final year students $(\mathrm{p}=0.00<0.05)$.(figure 5) $11.58 \%$ fourth year and $44.21 \%$ answered correctly to the question, what is the most widely used medicament for dry sockets as alvogyl. There was a statistical significance and more interns answered correctly when compared to final year students( $p=0.016<0.05)$. (figure 6)

Figure 3: Represents association between the response to the question, activation of which pathway leads to dry sockets . X axis represents year of study and $\mathrm{Y}$ axis represents the number of participants. $53.68 \%$ participants chose the most apt answer which was plasminogen pathway activation causes dry sockets (green). The association of response to the year of study was statistically significant with $p$ value $=0.036<0.05$ using chi square test, showing that intern students were more sure of the correct answer compared to the final year students.

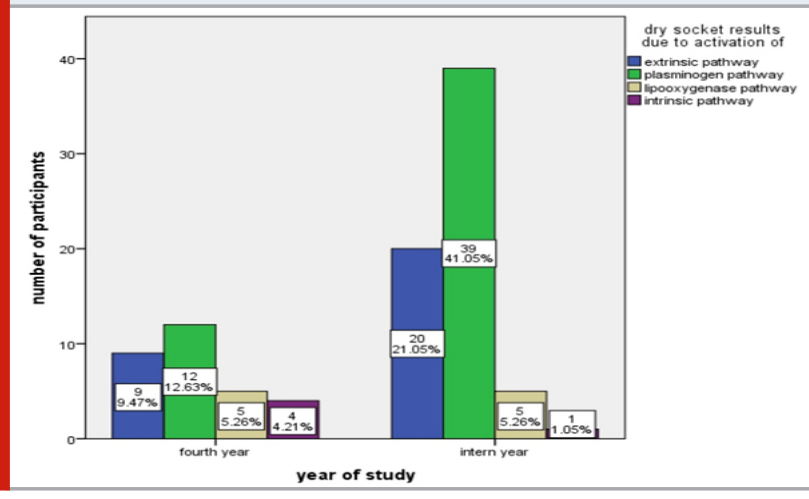

Figure 4: Represents association between the response to the question, incidence of dry socket occurs after how many days. $\mathrm{X}$ axis represents year of study and $\mathrm{Y}$ axis represents the number of participants. $63.16 \%$ participants knew the correct answer that dry socket incidence is seen 2-5 days following extraction (green). The association of response to the year of study was not statistically significant with $p$ value $=0.14>0.05$ using chi square test.

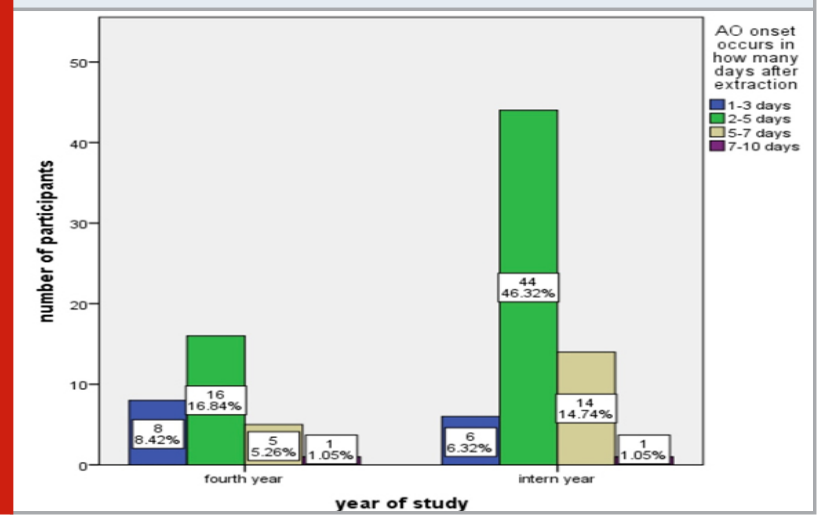

Figure 5: Represents association between the response to the question, is smoking a risk factor for the dry sockets. $\mathrm{X}$ axis represents year of study and $\mathrm{Y}$ axis represents the number of participants. 86.31\% participants agreed that smoking is a risk factor for the incidence of dry sockets(purple). The association of response to the year of study was of high statistical significance with $\mathrm{p}$ value $=0.0$ $>0.05$ using chi square test, showing that intern students were were more aware that smoking is a predisposing factor to AO.

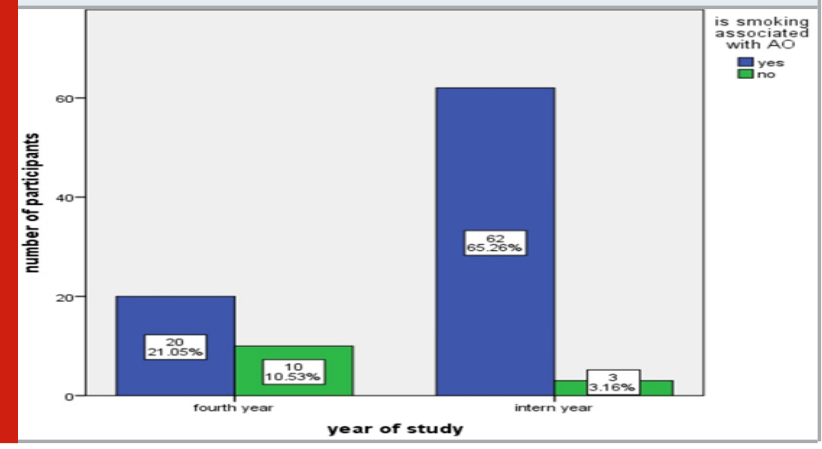

Figure 6: Represents association between the response to the question, which medicament is the most widely used medicament for dry sockets .X axis represents year of study and $\mathrm{Y}$ axis represents the number of participants. $55.79 \%$ participants agreed that alvogyl is the most widely used medicament for dry sockets(white). The association of response to the year of study was statistically significant with $\mathrm{p}$ value $=0.016<0.05 \mathrm{using}$ chi square test.

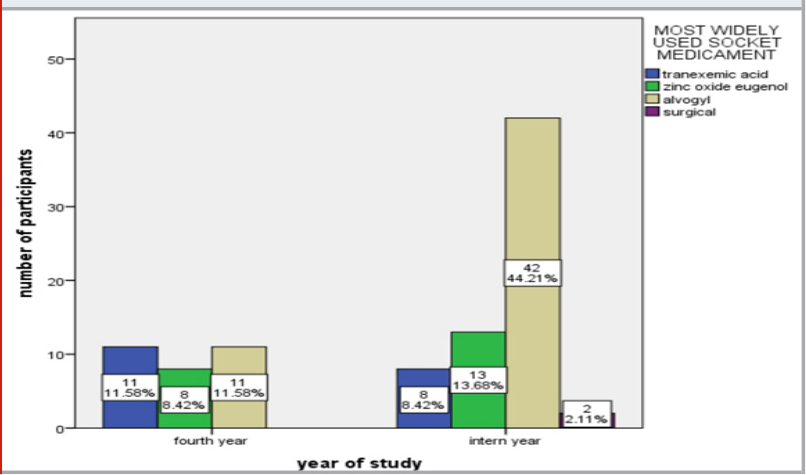

Dry sockets or fibrinolytic alveolitis or alveolitis sicca dolorosa is one of the most common complaints following extraction of teeth.(Alexander, 2000) There is a variation in the existence of dry sockets where the most common existence being in the mandibular third molar region following the extraction of the tooth.(Lilly et al., 1974) The study by Mohammed B Younis,et al. showed that there was an overall incidence of dry sockets in patients with an incidence of 3.2\%, approximately $1 \%$ to $5 \%$ of all extractions and in up to $38 \%$ of mandibular third molar extractions.(H, 2011). Our survey showed that most students were aware about the common site of incidence of dry socket.

Dry socket is caused mainly due to the disintegration of the blood clot by fibrinolysis.(Krekmanov, 1981) 
Plasminogen, the precursor of plasmin, circulates in the blood and binds to clots at wound sites. It is an important molecule that aids in the formation of blood clot, helping to induce fibrinolysis in the wound site. In cases of dry sockets there is lack of blood flow at the site because of bacterial and food debris present over the site of the wound, thereby delaying the healing of the extraction site and causing ischemia (Syrovets et al., 2012). This ischemia prevents initial blood clot to reform through additional bleeding and may prevent the immune system to act the site through local capillaries to initiate an inflammatory response to resorb the necrotic bone cells. (Chapin and Hajjar, 2015) 53.58\% students were able to answer this correctly among which $41.05 \%$ were intern students.

The incidence of dry sockets was mainly observed after 2-5 days following post extraction. The food particles and bacteria present inside the extraction socket hinder the healing of the wound and lead to the formation of toxins, causing irritation to the exposed bone leading to acute to chronic pain at the site of occlusion.(Porter, 1989) Many factors like smoking, use or oral contraceptive could trigger the formation of alveolar osteitis. Smoking and use of oral contraceptives both facilitate blood clotting throughout the body which can reduce blood circulation into the extraction socket correlating with the increased incidence of dry socket lesions in an individual.(Meechan et al., 1988) Our study correlates with this statement as $21.05 \%$ fourth year students and 65.25\% interns were aware of smoking increasing the chances for the incidence of dry sockets and 10.53\% fourth year students and $35.79 \%$ interns were aware that the use of oral contraceptives increased the chances for the incidence of dry sockets.

The basic treatment for dry sockets involves irrigation of the sockets using saline or chlorhexidine gluconate. The debris is completely removed and followed by the application of intraoral medicament like zinc oxide eugenol, povidine iodine and alvogyl.(Kolokythas et al., 2010) Pain relief is considered the primary goal of treatment in case of dry socket. The composition of both Alvogyl and Zinc oxide eugenol contains eugenol acting as sedative as well as having antibacterial properties. Alvogyl also contains butamben (anesthetic) and iodoform (antimicrobial).(Bloomer, 2000). The response to questions on smoking as risk factor to alveolar osteitis and treatment of alveolar osteitis showed statistically more correct responses from the intern students.

This difference can probably be due to the more clinical and practical exposure of intern students when compared to the fourth year dental students. Alveolar osteitis, being one of the most common complications that can be encountered during dental practise needs to be well understood by all dental practitioners. This post extraction complication can be very painful interfering with the patients regular activities. Hence, it is of utmost importance that as ongoing dental practitioners, students have a clear knowledge on the etiology, mechanism, clinical features and management of dry socket. Proper knowledge on the techniques followed by the dentist is necessary to reduce traumatic extractions. The education of patients on proper healthy practices is necessary to reduce the incidence of post extraction complications. Post extraction instructions should be given carefully to the patients to reduce improper practices following extraction of the tooth.

\section{CONCLUSION}

The survey showed that both final year and intern students displayed an overall good knowledge about dry socket and its management. However, intern students showed better understanding than fourth year students which was statistically significant. It can be concluded that dental students eventually gain better insight in the subject with increasing clinical years. However, not all students were clear with the topic of interest. This emphasises the importance of the need for one on one viva and training to ensure every student is equally competent.

\section{ACKNOWLEDGEMENTS}

The authors express their sincere gratitude to all the respondents who had willingly participated in the study

Conflict of Interest: There were no conflicts of interest as defined by the authors.

\section{REFERENCES}

Abdul Wahab PU, Senthil Nathan P, Madhulaxmi M, et al. (2017) Risk Factors for Post-operative Infection Following Single Piece Osteotomy. Journal of maxillofacial and oral surgery 16(3): 328-332. DOI: 10.1007/s12663-016-0983-6.

Abhinav RP, Selvarasu K, Maheswari GU, et al. (2019) The Patterns and Etiology of Maxillofacial Trauma in South India. Annals of maxillofacial surgery 9(1): 114-117. DOI: 10.4103/ams.ams_233_18.

Alexander RE (2000) Dental extraction wound management: A case against medicating postextraction sockets. Journal of Oral and Maxillofacial Surgery. DOI: 10.1016/s0278-2391(00)90017-x.

Birn H (1970) Bacteria and fibrinolytic activity in 'dry socket'. Acta odontologica Scandinavica 28(6): 773-783. DOI: 10.3109/00016357009028246.

Birn H (1973) Etiology and pathogenesis of fibrinolytic alveolitis ('dry socket'). International Journal of Oral Surgery. DOI: 10.1016/s0300-9785(73)80045-6.

Bloomer CR (2000) Alveolar osteitis prevention by immediate placement of medicated packing. Oral surgery, oral medicine, oral pathology, oral radiology, and endodontics 90(3): 282-284. DOI: 10.1067/ moe.2000.108919.

Bowe DC, Rogers S and Stassen LFA (2011) The management of dry socket/alveolar osteitis. Journal of the Irish Dental Association 57(6): 305-310. Available 
at: https://www.ncbi.nlm.nih.gov/pubmed/22338284. Catellani JE, Harvey S, Erickson SH, et al. (1980) Effect of Oral Contraceptive Cycle on Dry Socket (Localized Alveolar Osteitis). The Journal of the American Dental Association. DOI: 10.14219/jada.archive.1980.0420. Chapin JC and Hajjar KA (2015) Fibrinolysis and the control of blood coagulation. Blood reviews 29(1): 17-24. DOI: 10.1016/j.blre.2014.09.003.

Eapen BV, Baig MF and Avinash S (2017) An Assessment of the Incidence of Prolonged Postoperative Bleeding After Dental Extraction Among Patients on Uninterrupted Low Dose Aspirin Therapy and to Evaluate the Need to Stop Such Medication Prior to Dental Extractions. Journal of maxillofacial and oral surgery 16(1): 48-52. DOI: 10.1007/s12663-0160912-8.

Freudenthal N, Sternudd M, Jansson L, et al. (2015) A Double-Blind Randomized Study Evaluating the Effect of Intra-Alveolar Chlorhexidine Gel on Alveolar Osteitis After Removal of Mandibular Third Molars. Journal of Oral and Maxillofacial Surgery. DOI: 10.1016/j. joms.2014.08.035.

H AYM (2011) Dry Socket: Frequency, Clinical Picture, and Risk Factors in a Palestinian Dental Teaching Center. The Open Dentistry Journal. DOI: 10.2174/1874210601105010007.

Jain M and Nazar N (2018) Comparative Evaluation of the Efficacy of Intraligamentary and Supraperiosteal Injections in the Extraction of Maxillary Teeth: A Randomized Controlled Clinical Trial. The journal of contemporary dental practice 19(9): 1117-1121. DOI: 10.5005/jp-journals-10024-2391.

J PC, Marimuthu T, C K, et al. (2018) Prevalence and measurement of anterior loop of the mandibular canal using CBCT: A cross sectional study. Clinical implant dentistry and related research 20(4): 531-534. DOI: 10.1111/cid.12609.

Kolokythas A, Olech E and Miloro M (2010) Alveolar Osteitis: A Comprehensive Review of Concepts and Controversies. International Journal of Dentistry. DOI: 10.1155/2010/249073.

Krekmanov L (1981) Alveolitis after operative removal of third molars in the mandible. International journal of oral surgery 10(3): 173-179. DOI: 10.1016/s03009785(81)80051-8.

Kumar V, Patil K and Munoli K (2015) Knowledge and attitude toward human immunodeficiency virus/ acquired immuno deficiency syndrome among dental and medical undergraduate students. Journal of Pharmacy and Bioallied Sciences. DOI: 10.4103/09757406.163598.

Lilly GE, Osbon DB, Rael EM, et al. (1974) Alveolar osteitis associated with mandibular third molar extractions. The Journal of the American Dental Association. DOI: 10.14219/jada.archive.1974.0168. Mamoun J (2018) Dry Socket Etiology, Diagnosis, and Clinical Treatment Techniques. Journal of the Korean
Association of Oral and Maxillofacial Surgeons 44(2): 52-58. DOI: 10.5125/jkaoms.2018.44.2.52.

Marimuthu M, Andiappan M, Wahab A, et al. (2018) Canonical Wnt pathway gene expression and their clinical correlation in oral squamous cell carcinoma. Indian journal of dental research: official publication of Indian Society for Dental Research 29(3): 291-297. DOI: 10.4103/ijdr.IJDR_375_17.

Meechan JG, Macgregor ID, Rogers SN, et al. (1988) The effect of smoking on immediate post-extraction socket filling with blood and on the incidence of painful socket. The British journal of oral \& maxillofacial surgery 26(5): 402-409. DOI: 10.1016/0266-4356(88)90093-9.

Nusair YM and Abu Younis MH (2007) Prevalence, Clinical Picture, and Risk Factors of Dry Socket in a Jordanian Dental Teaching Center. The Journal of Contemporary Dental Practice. DOI: 10.5005/jcdp-83-53.

Patil SB, Durairaj D, Suresh Kumar G, et al. (2017) Comparison of Extended Nasolabial Flap Versus Buccal Fat Pad Graft in the Surgical Management of Oral Submucous Fibrosis: A Prospective Pilot Study. Journal of maxillofacial and oral surgery 16(3): 312-321. DOI: 10.1007/s12663-016-0975-6.

Porter BT (1989) The effect of smoking on immediate post-extraction socket filling with blood and on the incidence of painful socket. Journal of Oral and Maxillofacial Surgery. DOI: 10.1016/02782391(89)90305-4.

Ramadorai A, Ravi P and Narayanan V (2019) Rhinocerebral Mucormycosis: A Prospective Analysis of an Effective Treatment Protocol. Annals of maxillofacial surgery 9(1): 192-196. DOI: 10.4103/ams. ams_231_18.

Senthil Kumar MS, Ramani P, Rajendran V, et al. (2019) Inflammatory pseudotumour of the maxillary sinus: clinicopathological report. Oral Surgery 12(3): 255-259. DOI: $10.1111 /$ ors. 12409 .

Sharma A, Aggarwal N, Rastogi S, et al. (2017) Effectiveness of platelet-rich fibrin in the management of pain and delayed wound healing associated with established alveolar osteitis (dry socket). European Journal of Dentistry. DOI: 10.4103/ejd.ejd_346_16. Sweta VR, Abhinav RP and Ramesh A (2019) Role of Virtual Reality in Pain Perception of Patients Following the Administration of Local Anesthesia. Annals of maxillofacial surgery 9(1): 110-113. DOI: 10.4103/ams. ams_263_18.

Syrovets T, Lunov 0 and Simmet T (2012) Plasmin as a proinflammatory cell activator. Journal of leukocyte biology 92(3): 509-519. DOI: 10.1189/jlb.0212056.

Wahab PUA, Madhulaxmi M, Senthilnathan P, et al. (2018) Scalpel Versus Diathermy in Wound Healing After Mucosal Incisions: A Split-Mouth Study. Journal of oral and maxillofacial surgery: official journal of the American Association of Oral and Maxillofacial Surgeons 76(6): 1160-1164. DOI: 10.1016/j.joms.2017.12.020. 